$$
\begin{gathered}
\text { CONE-970726--1 } \\
\text { WAPD-T- } 3132
\end{gathered}
$$

\title{
A DEMONSTRATION OF MITIGATION OF ENVIRONMENTALLY-ASSISTED CRACKING BY THE APPLICATION OF A TENSILE OVERLOAD
}

\section{$\cos 2 \cos 3$ \\ $08 \mathrm{TI}$}

L. A. James

U. S. Department of Energy Contract DE-AC11-93PN38195

Proposed for Submittal to the 1997 ASME Pressure Vessel and Piping Conference

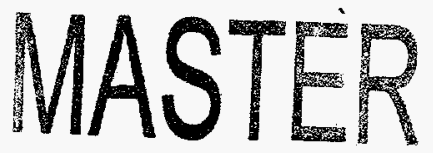

\section{DISCLAIMER}

This report was prepared as an account of work sponsored by an agency of the United States Government. Neither the United States Government nor any agency thereof, nor any of their employees, makes any warranty, express or implied, or assumes any legal liability or responsibility for the accuracy, completeness, or usefulness of any information, apparatus, product, or process disclosed, or represents that its use would not infringe privately owned rights. Reference herein to any specific commercial product, process, or service by trade name, trademark, manufacturer, or otherwise does not necessarily constitute or imply its endorsement, recommendation, or favoring by the United States Government or any agency thereof. The views and opinions of authors expressed herein do not necessarily state or reflect those of the United States Government or any agency thereof. 


\section{DISCLAIMIER}

Portions of this document may be illegible in electronic image products. Images are produced from the best available original document. 


\title{
A DEMONSTRATION OF MITIGATION OF ENVIRONMENTALLY-ASSISTED CRACKING BY THE APPLICATION OF A TENSILE OVERLOAD
}

\author{
L. A. James* \\ Advisory Engineer \\ Bettis Atomic Power Laboratory \\ Westinghouse Electric Corporation \\ West Mifflin, PA 15122-0079
}

\begin{abstract}
Environmentally-assisted cracking (EAC) of low-alloy steels in elevated temperature aqueous environments is readily observed in many laboratory experiments conducted in autoclaves, yet the observation of EAC in actual components operating in the same environments is quite rare. Mass transport of sulfides from the crack enclave by diffusion and convection occurring in operating components provides one plausible explanation to this apparent paradox. Another contribution to EAC mitigation may also arise from the nonconstant stress amplitudes typical for many operating components. This paper provides a demonstration of how a single tensile overload to 40-percent above a steady-state maximum fatigue stress can retard subsequent crack growth at the steady-state level for a sufficient period of time that diffusional mass transport can reduce the crack-tip sulfide concentration to a level below that necessary to sustain EAC.
\end{abstract}

\section{INTRODUCTION}

Environmentally-assisted cracking (EAC) of low-alloy steels in high-temperature aqueous environments typical of those employed in light-water reactor (LWR) systems has been a subject of considerable interest since the pioneering work of Kondo et al (1972a, 1972b) demonstrated significantly higher fatigue crack propagation (FCP) rates in water than would be expected in an air environment under similar conditions. A large number of research studies have been directed at the EAC issue, and the results of these studies have been summarized in a series of review articles (e.g., Tice, 1985; Bullock 1989; James, 1995a) each one of which represents an update in the current state of knowledge. The basic cause-andeffect relationship for EAC has been known for several years, and considerable progress has been made in quantifying the conditions under which EAC will, or will not, occur in a given situation. Quantifying the conditions under which EAC will occur is an important consideration because experience has shown that EAC occurs rather easily in autoclave experiments, yet the phenomenon is clearly not endemic amongst commercial LWR systems worldwide.

This paper will briefly discuss some of the mitigating factors that help explain why the occurrence of EAC is a relatively rare event in actual LWR operating systems. However, the main objective of this paper is to describe a demonstration of an additional possible mitigating factor: the mitigation of EAC by the application of a tensile overload. 


\section{REVIEW OF EAC CAUSES AND MITIGATION}

It has been recognized EAC occurs in a lowalloy steel undergoing cyclic loading in an aqueous environment when the concentration of hydrogen sulfide at the crack tip reaches a critical level; probably about $5 \pm 2$ ppb $\mathrm{H}_{2} \mathrm{~S}$ NanDerSluys, 1993). EAC manifests itself by exhibiting FCP rates considerably higher (sometimes by a factor of 40-100) than would be expected in an air environment under the same conditions.

The occurrence or non-occurrence of EAC is essentially a function of the local crack tip balance between the competing processes of sulfide supply and sulfide loss. In lieu of water-borne sulfur contamination, the only source of sulfides to the crack tip is the growing crack itself, which intersects metallurgical sulfide inclusions (MnS, FeS, etc.) embedded within the steel. These inclusions then dissolve in the aqueous crack-tip environment (Matsushita et al. 1991) and supply sulfide ions to the crack tip. Sulfides can be removed from the crack-tip region by any one, or more, of four mass-transport processes: 1) diffusion due to a sulfide concentration gradient from the crack tip to the crack mouth (e.g., Turnbull, 1982, 1992; Wire, 1996), 2) ion migration due to an electrochemical corrosion potential $(E C P)$ gradient from the crack tip to the crack mouth (e.g., Turnbull, 1982), 3) fatigue "pumping" or advection due to cyclic motion of the crack walls (e.g., Hartt, 1978; Turnbull, 1983), and 4) convective transport induced within the crack enclave by an external (to the crack) stream flow (e.g., James, 1995b, 1997a). Not all of these mass-transport processes play a significant role in every case of corrosion-fatigue crack growth. For example, the second process, ion migration, is probably an important factor in the case of oxygenated BWR environments, where a significant ECP gradient can exist between the crack tip and the crack mouth. Potential gradients between the crack tip and crack mouth are much smaller for low-oxygen PWR environments (Gabetta, 1987). The third mass-transport process, fatigue "pumping", is likely to be a factor only at relatively high cyclic frequencies, and the fourth process, convective mass transport, would not be an important consideration under quasistagnant flow conditions. Note, however, that the first mass-transport process, diffusion, would be operative any time that a sulfide concentration gradient exists between the crack tip and the crack mouth. In fact, diffusion was essentially the only masstransport operative in the experiment to be described herein because it was conducted in low-oxygen water at low cyclic frequencies under quasi-stagnant flow conditions.

Many corrosion-FCP experiments exhibit $E A C$ at, or near, the start of the experiment. Combrade et al. (1988) have pointed out that the majority of specimens to be used in corrosion-FCP experiments are precracked in an air environment prior to insertion into the autoclave, and that the undissolved sulfide inclusions on the crack flanks can predispose the specimen toward the early exhibition of EAC. In many cases, EAC then persists throughout the entire experiment because the high EAC-related FCP rates continue to expose embedded sulfide inclusions at a rate sufficient to ensure that crack-tip sulfide concentrations exceed the critical level; i.e., a high rate of sulfide supply to the crack tip. Wire and $L i(1996)$ have shown that even with high-sulfur steels in quasi-stagnant water, EAC does not initiate from an initially "clean" crack (i.e., $\mathrm{H}_{2} \mathrm{~S}<<$ "critical" concentration) until the average crack velocity, $V$, exceeds a critical level, $V_{t n}$, and maintains that velocity for a minimum critical crack extension, $\Delta a_{\text {conit; }}$ i.e.

$$
\begin{aligned}
V \geq V_{\text {in }} & =\left(5 \times 10^{-7}\right)(2.54 / a) \\
& =1.27 \times 10^{-6} / \mathrm{a}
\end{aligned}
$$

and

$$
\Delta \mathrm{a} \geq \Delta \mathrm{a}_{\text {crt }}=0.33 \mathrm{~mm}
$$


where the dimensions of $\mathrm{V}$ and $\mathrm{a}$ are $\mathrm{mm} / \mathrm{s}$ and $\mathrm{mm}$, respectively. In this context, the crack velocity is defined as the crack extension for an increment of time divided by the total time associated with that cracking increment. The total time includes all time spent with stresses increasing, stresses decreasing, plus hold or dwell periods. Wire and $\mathrm{L}$ conducted most of their experiments on specimens having an initial precrack depth (from the notch) of $2.54 \mathrm{~mm}$. Since diffusional mass transport, and hence the EAC Initiation Velocity $V_{n}$, is linearly related to the crack depth, the normalizing term (2.54/a) was incorporated into Equation [1a].

The EAC Initiation Criterion of Equation [1] applies to the initiation of EAC in high-sulfur steels in a quasi-stagnant low-oxygen environment; i.e., diffusional mass transport is the only operative process for removing sulfides from the crack tip. Similar considerations can be applied to the cessation of an operative case of EAC in high-sulfur steels in a quasi-stagnant lowoxygen environment. Other scenarios for the cessation of an operative case of EAC include convective mass transport (James, 1995b, 1996) as well as the present study on tensile overload mitigation.

\section{EXPERIMENTAL PROCEDURES}

The steel utilized in this experiment was a high-sulfur heat of ASTM A508-2 (Heat 15812). This heat has been employed in previous experiments on corrosion-FCP in low-oxygen aqueous environments, and readily exhibits EAC at temperatures of $243^{\circ} \mathrm{C}$ (James, 1994) and $288^{\circ} \mathrm{C}$ Nan Der Sluys and Emanuelson, 1993) when special measures are not taken to reduce the crack-tip sulfide concentration prior to commencing fatigue testing. The specimen for the present study, as well as those for the previous studies, was machined from the reactor pressure vessel nozzle that was removed from an unfinished commercial nuclear plant. The chemical composition and room temperature mechanical properties of this heat are given in Tables I and II, respectively.

The specimen employed was a " $2 T^{\text {" }}$ compact tension specimen $(W=5.08 \mathrm{~mm}$ ). Crack lengths were inferred from compliance measurements using an in-situ displacement transducer and the standard compliance relationship of Saxena and Hudak (1978). Stress intensity factors, $K$, were calculated using the standard relationship given by Saxena and Hudak.

Deaerated water containing about $40 \mathrm{cc}$ $\mathrm{H}_{2} / \mathrm{kg} \mathrm{H}_{2} \mathrm{O}$ was employed in this study. Dissolved $\mathrm{O}_{2}$ was therefore generally less than $10 \mathrm{ppb}$. The room temperature $\mathrm{pH}$ was in the range 10.2 to 10.3 , while the calculated $^{\star \star} \mathrm{pH}$ at the test temperature of $243^{\circ} \mathrm{C}$ was 6.8. The room temperature conductivity averaged about $50 \mu \mathrm{S} / \mathrm{cm}$. The ECP was measured throughout the experiment using a $\mathrm{Ag} / \mathrm{AgCl}$ reference electrode. The measurements were corrected to standard hydrogen electrode (SHE) conditions using the relationship of Macdonald et al. (1979). These results are plotted in Figure 1. The mean ECP value of $-0.728 V_{S H E}$ is in good agreement with earlier measurements in similar environments at $243^{\circ} \mathrm{C}$ (James, 1994, 1997a, 1997b, 1997c).

The specimen was cyclically-loaded by a computer-controlled servo-hydraulic apparatus operating in the constant- $\Delta K$ mode. A "positive sawtooth" loading waveform was utilized with 85-percent loadrise time, 15-percent load-fall time, and no dwell period within or between fatigue cycles. With the exception of the intentionally-applied tensile overloads, the testing was done under "steady-state" 
cycling conditions: $\quad K_{\max }=$ $21.98 \mathrm{MPa} \sqrt{\mathrm{m}}(20 \mathrm{ksi} \sqrt{\mathrm{in}})$,

$R=K_{\operatorname{man}} / K_{\operatorname{mex}}=0.5$, and a cyclic frequency of $0.0167 \mathrm{~Hz}$ with a load-rise time of 51 seconds.

\section{RESULTS AND DISCUSSION}

It has been recognized for over thirty-six years that the application of a tensile overload can retard subsequent crack growth rates (Hudson and Hardrath, 1961). Considerable research effort has been expended on the subject of overload retardation since the early work of Hudson and Hardrath. Scores of journal papers have been published on the subject, resulting in dozens of analytical models, or model variants, on the prediction of overload effects. The success of some of these models has been inconsistent; they generally do a reasonable job of describing the observed results, but often lack the generality to be extended to other conditions. The objective of the present experiment was not to stop crack extension entirely; this could be accomplished merely with the application of a single massive tensile overload. The objective was, instead, to demonstrate that a more moderate degree of overload could retard crack growth rates (which had previously been at the EAC level) to a level such that diffusional mass transport could reduce the crack-tip sulfide level below that necessary to sustain EAC.

In spite of the variety of overload retardation models, virtually all models have a common feature: they all attempt to model the zone of residual compressive stresses at the crack tip and the attendant change in crack closure that results from the overload. This is illustrated schematically in Figure 2. Figure 2a shows the crack-tip plastic zone at the application of the tensile overload. Prior to the overload it is presumed that fatigue cycling was occurring at a lower level of $\sigma_{\max } ;$ hence, a steady-state plastic zone smaller than the overload plastic zone that is pictured. Note that the stress distribution ahead of the crack tip in Figure 2a has the expected profile. Following the tensile overload, it is presumed that fatigue cycling returns to the earlier steady-state conditions. Figure $2 b$ shows the stress distribution ahead of the crack tip following the tensile overload. Note that there is a relatively large zone of residual compressive stresses ahead of the crack tip. These residual stresses will partially, or wholly, offset the applied tensile stresses during the subsequent steady-state cycling. The magnitude of the overload, and the resulting zone of compressive stress will, of course, determine whether the subsequent crack growth rates will be partially or totally retarded. The opposite effect can also be operative: the application of a compressive underload can create tensile residual stresses at the crack tip which can locally accelerate crack growth rates (Rice and Stephens, 1973). This will be discussed in more detail later.

Figure 3 illustrates schematically the cyclic history of the experiment. With the exception of the planned overloads, fatigue cycling proceeded under the "steady-state" constant- $\Delta \mathrm{K}$ conditions. The first single overload to 10-percent over $K_{\max }$ occurred at 5385 cycles. Steady-state cycling then resumed until another single overload to 20-percent over $K_{\max }$ was applied at a total cycle count of 15,730 cycles. Steady-state cycling then resumed again until another single overload was applied at a total cycle count of 25,718 cycles to 40-percent over $K_{\max }$. Steady-state cycling then resumed following the last overload, and continued until the end of the experiment at a total of 38,790 cycles. The crack length versus cycles results are plotted in Figure 4.

As discussed earlier, EAC readily occurs in this heat of A508-2 steel when tested under conditions conducive to EAC. This is illustrated in Figure 5 where earlier results from James (1994) are plotted in terms of the time-domain format originally introduced by Shoji et al. (1981, 1983). In the time domain format, the ordinate is the 
experimentally-observed FCP rate (da/dN) divided by the load-rise time, while the abscissa is the mean FCP rate expected in an air environment at that value of $\Delta K$ and $R$ (Eason et al., 1989) divided by the load-rise time.

Test Phase I of the present study was conducted under the "Steady-State" conditions, and as will be seen in Figure 6 , EAC rates were observed that were in good agreement with the earlier results in Figure 5. The application of a 10-percent overload resulted in only a mildly-retarded FCP rate (Figure 4), and as shown in Figure 6, Test Phase 2 continued under EAC conditions. The application of a 20-percent overload produced a somewhat greater FCP retardation in Test Phase 3a (Figure 4), and Figure 6 shows that the FCP rate was intermediate to the EAC and non-EAC extremes. However, although retarded, the average crack velocity during Test Phase $3 a$ was $V=5.59 \times 10^{-7} \mathrm{~mm} /$ second. The average depth (from the notch) at this point was $17.65 \mathrm{~mm}$, and per Equation [1a] the EAC Initiation Velocity would be expected to be $V_{m}=7.20 \times 10^{-8} \mathrm{~mm} / \mathrm{second}$. Hence, since the average crack velocity for Test Phase 3a exceeded the EAC Initiation Velocity by factor of approximately 7.8 , the retardation observed during Test Phase $3 a$ would be expected to be temporary, and EAC would be expected to resume. This is indeed what happened during Test Phase $3 b$, and as may be seen in Figure 6 , a "full" case of EAC resumed. The application of a 40-percent overload produced a significant degree of retardation in the FCP rates as shown in Figures 4 and 6. Note that crack extension had not ceased entirely, but that it was proceeding at such a low rate that is entirely likely that diffusional mass transport would reduce crack-tip sulfide concentration to a value less than the critical concentration (Wire and $L$, 1996). During period of retardation, the FCP rates would gradually increase and approach the air or non-EAC levels only as the crack extended beyond the overload plastic zone. Any subsequent reinitiation of
EAC would depend upon whether the subsequent average crack velocity exceeded $V_{m} ;$ e.g., the criterion of Equation [1].

Because steady-state FCP rates cannot resume until the crack extends beyond the overload plastic zone, the present experiment was designed to provide several plastic zone diameters between each overload. Mills et al. (1977) found that, for ASTM A514-F steel, a crack extension of about two plastic zone diameters (based on a Dugdale yield model, Dugdale, 1960) was required between overloads to minimize overload interaction.

The crack-tip plastic zone radius $\left(r_{p}\right)$ is a function of the applied K-level and the material yield strength $\left(\sigma_{y}\right)$. Table $\|$ shows that the room temperature yield strength of this heat of material is $468 \mathrm{MPa}$. The value of $\sigma_{y}$ for this heat at $243^{\circ} \mathrm{C}$ is not known, but results for similar steels suggest that $\sigma_{\mathrm{y}}$ at $243^{\circ} \mathrm{C}$ should be about 90-percent of the room temperature value; hence, a value of $\sigma_{\mathrm{y}}=421 \mathrm{MP}_{\mathrm{a}}$ will be used for $243^{\circ} \mathrm{C}$.

The simple Irwin (1968) plastic zone radius (smaller than the Dugdale plastic zone used in Mills et al. (1977), but perhaps better suited for the present class of steel) can be expressed as

$$
r_{p}=\frac{1}{2 \pi}\left[\frac{K_{\max }}{\sigma_{y}}\right]^{2} \quad \text { Eq. [2] }
$$

for "plane stress" conditions, and

$$
r_{p}=\frac{1}{6 \pi}\left[\frac{k_{\max }}{\sigma_{y}}\right]^{2} \quad \text { Eq. [3] }
$$

for "plane strain" conditions. Since typical test specimens are generally not in a stress state corresponding to either of the above extremes, the crack-tip plastic zone radius is often estimated using an intermediate approximation: 


$$
r_{p}=\frac{1}{4 \pi}\left(\frac{K_{\max }}{\sigma_{y}}\right)^{2} \quad \text { Eq. [4] }
$$

Based on Equation [4], and employing $\sigma_{y}=$ $421 \mathrm{MPa}$, the plastic zone radil for the $10 \%$, $20 \%$, and $40 \%$ overloads applied during this experiment are estimated to be $0.254,0.305$, and $0.432 \mathrm{~mm}$, respectively. Mills et al. (1977) found that a crack extension of about two Dugdale yield zones (approximately $4 r_{p}$ per Eq. [4]) was required between overloads to minimize overload interaction. It will be noted in Figure 4 that, with the exception of Test Phase 4, the crack was extended several plastic zone sizes between each overload.

\section{CONCLUDING REMARKS}

The present experiment clearly demonstrates that mitigation of an on-going case of EAC is possible with the application of a tensile overload of reasonable magnitude. Whether or not EAC subsequently reinitiates depends entirely upon the subsequent load cycling history. If, for example, EAC was operative and the fatigue crack growth rates had been temporarily retarded by the application of a tensile overload of the 40-percent magnitude in the present experiment, EAC might never re-initiate if the subsequent loading history included a significant period of cyclic inactivity (e.g., taking the unit out of service for a while) or subsequent operation involving less frequent loadings.

Although it is a useful demonstration of how a tensile overload can lead to mitigation of EAC, the present experiment is probably overly simplistic relative to more realistic loading histories. Actual loading histories could be considerably more complex than the simple loading schemes employed in this demonstration experiment.* Single tensile overloads were employed in the present experiment. Multiple tensile overloads applied consecutively have a greater crack growth retardation effect than single tensile overloads (Milis et al., 1977). Retardation is even greater when the multiple tensile overloads are separated by some critical amount of crack extension (Mills and Hertzberg, 1976). In addition, when a single tensile overload is directly followed by a single compressive underload, the subsequent crack growth retardation is minimized (although not eliminated) (Mills and Hertzberg, 1976). On the other hand, when only compressive underloads are applied, subsequent crack growth rates are actually temporarily accelerated until the crack reaches the boundary of the underload-affected plastic zone (Rice and Stephens, 1973). This can be thought of as the inverse of the situation pictured in Figure 2; a zone of residual tensile stresses due to the compressive underload results in temporarily higher local crack growth rates. Ignoring compressive underloads could result in non-conservative predictions of crack extension.

In spite of the simplistic nature of this experiment, it does provide additional insight into why the phenomenon of environmentally-assisted cracking is apparently not widely observed in many operating systems.

\footnotetext{
*Variable-amplitude loading experiments have been conducted on medium-sulfur steels in a PWR environment at $288^{\circ} \mathrm{C}$ (Bamford, 1988; Cullen and Broek, 1989). The loading spectrum was designed to be at least partially prototypic of a commercial PWR plant. However, since EAC was not observed in this medium-sulfur steel under constant load-amplitude loadings, the authors did not have to deal with the additional modeling complications of time-dependent mass transport.
} 


\section{ACKNOWLEDEMENTS}

This work was performed under a U. S. Department of Energy contract with the Bettis Atomic Power Laboratory, a unit of the Westinghouse Electric Corporation. The experimental work was conducted under a subcontract with the Babcock and Wilcox Research Center. The author wishes to acknowledge the efforts of J. V. Monter and C. S. Wade of B\&W in helping make the experiment a success. In addition, the author acknowledges the helpful discussions with a colleague, Dr. W. J. Mills.

\section{REFERENCES}

Bamford, W. H., 1988, "A Summary of Environmentally Assisted Crack-Growth Studies Performed at Westinghouse Electric Corporation: Under Funding from the Heavy-Section Steel Technology Program," NUREG/CR-5020

Bulloch, J. H., 1989, "A Review of the Fatigue Crack Extension Behaviour of Ferritic Reactor Pressure Vessel Materials in Pressurised Water Reactor Environments," Res Mechanica, Vol. 26, No. 2, pp. 95-172

Combrade, P., Foucault, M. and Slama, G., 1988, "Effect of Sulfur on the Fatigue Crack Growth Rates of Pressure Vessel Steel Exposed to PWR Coolant: Preliminary Model for Prediction of the Transitions Between High and Low Crack Growth Rates", Proceedings of the Third International Conference, Environmental Degradation of Materials in Nuclear Power Systems - Water Reactors, G. J. Theus and J. R. Weeks (Eds.), TMS-AIME, pp. 269-276

Cullen, W. H., and Broek, D. 1989, "The Effects of Variable Amplitude Loading on a A533-B Steel in High Temperature Air and Reactor Water Environments", NUREG/CR-4929
Dugdale, D. S., 1960, Yielding of Steel Sheets Containing Slits", Journal of the Mechanics and Physics of Solids, Vol. 8, pp. 100-104

Eason, E. D., Andrew, S. P., Warmbrodt, S. B., Nelson, E. E. and Gilman, J. D., 1989, Analysis of Pressure Vessel Steel Fatigue Tests in Air," Nuclear Engineering and Design, Vol 115, No. 1, pp. 23-30

Gabetta, G., and Caretta, E., 1987, "Corrosion-Potential Measurements Inside and Outside a Growing Crack During Environmental Fatigue Tests at $288^{\circ} \mathrm{C}$, with Different Oxygen Contents," Corrosion Chemistry Within Pits, Crevices and Cracks, Her Majesty's Stationery Office, London, pp. $287-300$

Hartt, W. H., Tennant, J. S., and Hooper, W. C., 1978, Solution Chemistry Modification Within Corrosion-Fatigue Cracks," CorrosionFatigue Technology, ASTM STP 642, pp. 5-18

Hudson, C. M., and Hardrath, H. F., 1961, "Effect of Changing Stress Amplitude on the Rate of Fatigue Crack Propagation of Two Aluminum Alloys", NASA Technical Note D-960

Irwin, G. R., 1968, "Linear Fracture Mechanics, Fracture Transition, and Fracture Control", Engineering Fracture Mechanics, Vol. 1, No. 2, pp. 241-257

James, L A., 1994, "The Effect of Temperature and Cyclic Frequency Upon Fatigue Crack Growth Behavior of Several Steels in an Elevated Temperature Aqueous Environment," Journal of Pressure Vessel Technology, Vol. 116, No. 2, pp. 122-127

James, L A., 1995a, "EnvironmentallyAssisted Cracking of Ferritic Steels in Aqueous Environments: An Interpretive Review," Welding Research Council Bulletin 404, pp 1-20 
James, L. A., Wire, G. L., and Cullen, W. C., 1995b, "The Effect of Water Flow Rate Upon the Environmentally-Assisted Cracking Response of a Low-Alloy Steel," Journal of Pressure Vessel Technology, Vol. 117, No. 3, pp. 238-244

James, L A., Lee, H. B., and Wire, G. L., 1997a, The Effect of Water Flow Rate Upon the Environmentally-Assisted Cracking Response of a Low-Alloy Steel: Experimental Results Plus Modeling," ibid, Vol. 119, No. 1 , in press

James, L. A., Auten, T. A., Poskie, T. J., and Cullen, W. H., 1997b, "Corrosion-Fatigue Crack Growth in Clad Low-Alloy Steels: Part I, Medium-Sulfur Forging Steel," ibid., in press, (WAPD-T-3095)*

James, L A., Lee, H. B., Wire, G. L., Novak, S. R., and Cullen, W. H., 1997C, "CorrosionFatigue Crack Growth in Clad Low-Alloy Steels: Part II, Water Flow Rate Effects in High-Sulfur Plate Steel," ibid., in press, (WAPD-T-3096)*

Kondo, T., Kkuyama, T., Nakajima, H., and Shindo, M. and Nagasaki, R., 1972a, "Corrosion Fatigue of ASTM A-302B Steel in High Temperature Water, the Simulated Nuclear Reactor Environment," Corrosion Fatigue, NACE-2, National Association of Corrosion Engineers, pp. 539-556

Kondo, T., Kikuyama, T., Nakajima, H., and Shindo, M., 1972b, "Fatigue of Low-Alloy Steels in Aqueous Environment at Elevated Temperatures," Mechanical Behavior of Materials, Proceedings International Conference on Mechanical Behavior Materials, Vol. 3, The Society of Materials Science, Japan, pp. 319-327
Macdonald, D. D., Scott, A. C., and Wentrcek, P., 1979, "Silver-Silver Chloride Thermocells' and Thermal Liquid Junction Potentials for Potassium Chloride Solutions at Elevated Temperatures", Journal of the Electrochemical Society, Vol. 126, No. 9, pp. 1618-1624

Matsushima, S., Katoda, Y., Sato, S., and Nagata, N., 1991, "Dissolution Behavior of MnS Inclusions in Low Alloy Steels in High Temperature Water", Corrosion Control - 7th APCCC, Vol. 1, International Academic Publishers, Beijing, pp. 112-117

Mills, W. J., and Hertzberg, R. W., 1976, "Load Interaction Effects on Fatigue Crack Propogation in 2024-T3 Aluminum Alloy", Engineering Fracture Mechanics, Vol. 8, No. 4, pp. 657-667

Mills, W. J., Hertzberg, R. W., and Roberts, R., 1977, "Load Interaction Effects on Fatigue Crack Growth in A514F Steel Alloy", Cyclic Stress-Strain and Plastic Deformation Aspects of Fatigue Crack Growth, ASTM STP 637, pp. 192-208

Rice, R. C., and Stephens, R. I., 1973, "Overload Effects on Subcritical Crack Growth in Austenitic Manganese Steel", Progress in Flaw Growth and Fracture Toughness Testing, ASTM STP 536, pp. 95-114

Saxena, A., and Hudak, S. J., 1978, "Review and Extension of Compliance Information for Common Crack Growth Specimens", International Journal of Fracture, Vol. 14, No. 5 , pp. $453-468$

\footnotetext{
*Available from US DOE Office of Scientific Technical Information, P. O. Box 62, Oak Ridge, TN 37831
} 
Shoji, T., Takahashi, H., Suzuki, M., and Kondo, T., 1981, "A New Parameter for Characterizing Corrosion Fatigue Crack Growth," Journal of Engineering Materials and Technology, Vol. 103, No. 4, pp. 298-304

Shoji, T., Takahaski, H., Nakajima, H., and Kondo, T., 1983, "Role of Loading Variables in Environment Enhanced Crack Growth for Water-Cooled Nuclear Reactor Pressure Vessel Steels," NUREG/CP-OO44, Vol. 2, pp. 143-171

Tice, D. R., 1985, "A Review of the U.K. Collaborative Programme to Test the Effects of Mechanical and Environmental Variables on Environmentally Assisted Crack Growth of PWR Pressure Vessel Steels," Corrosion Science, Vol. 25, No. 8/9, pp. 705-743

Turnbull, A., and Thomas, J. G. N., 1982, "A Model of Crack Electrochemistry for Steels in the Active State Based on Mass Transport by Diffusion and Ion Migration," Journal of the Electrochemical Society, Vol. 129, No. 7, pp. 1412-1422

Turnbull, A., 1983, "A Theoretical Evaluation of the Oxygen Concentration in a CorrosionFatigue Crack", Corrosion-Fatigue: Mechanics, Metallurgy, Electrochemistry, and Engineering, ASTM STP 801, Pp. 351.366

VanDerSluys, W. A. and Emanuelson, R. H., 1993, "Environmental Acceleration of Fatigue Crack Growth in Reactor Pressure Vessel Materials", TR-102796, Vol.' 1 \& 2, EPRI

Wire, G. L. and Li, Y. Y., 1996, "Initiation of Environmentally-Assisted Cracking in Low-Alloy Steels," Fatigue and Fracture1996-Volume I, ASME Publication PVP-Vol. 323, pp. 269-289 


\section{Table 1}

Chemical Composition (\% weight) of Heat 15812

\begin{tabular}{ccccccccc}
$\mathrm{C}$ & $\mathrm{Mn}$ & $\mathrm{P}$ & $\mathrm{S}$ & $\mathrm{Si}$ & $\mathrm{Mo}$ & $\mathrm{Cu}$ & $\mathrm{Ni}$ & $\mathrm{Cr}$ \\
\hline 0.20 & 0.76 & 0.005 & 0.021 & 0.27 & 0.62 & - & 0.78 & 0.38 \\
0.21 & 0.75 & 0.003 & 0.024 & 0.27 & 0.71 & 0.16 & 0.76 & 0.38
\end{tabular}

Table II

Room Temperature Mechanical Properties of Heat 15812 (from VanDerSluys, 1993)

$\begin{array}{cccc}\begin{array}{c}0.2 \% \\ \text { Yield Strength }\end{array} & \begin{array}{c}\text { Ultimate } \\ \text { Strength }\end{array} & \text { Elongation } & \begin{array}{c}\text { Reduction of } \\ \text { Area }\end{array} \\ \begin{array}{c}67.9 \mathrm{ksi} \\ (468 \mathrm{MPa})\end{array} & \begin{array}{c}85.6 \mathrm{ksi} \\ (590 \mathrm{MPa})\end{array} & 27.0 \% & 56.2 \%\end{array}$




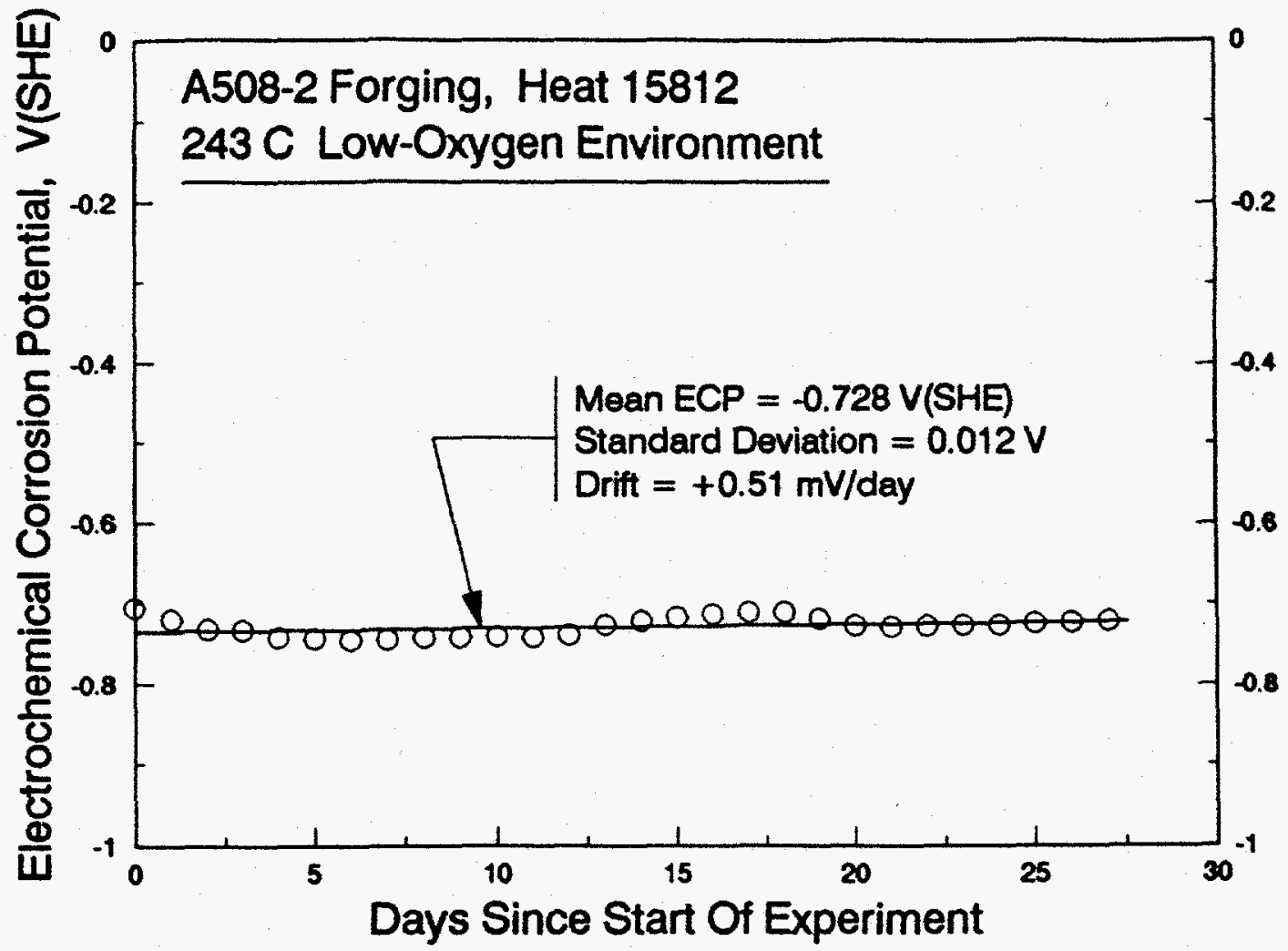

Figure 1. Electrochemical corrosion potential measurements (versus SHE) made throughout the experiment
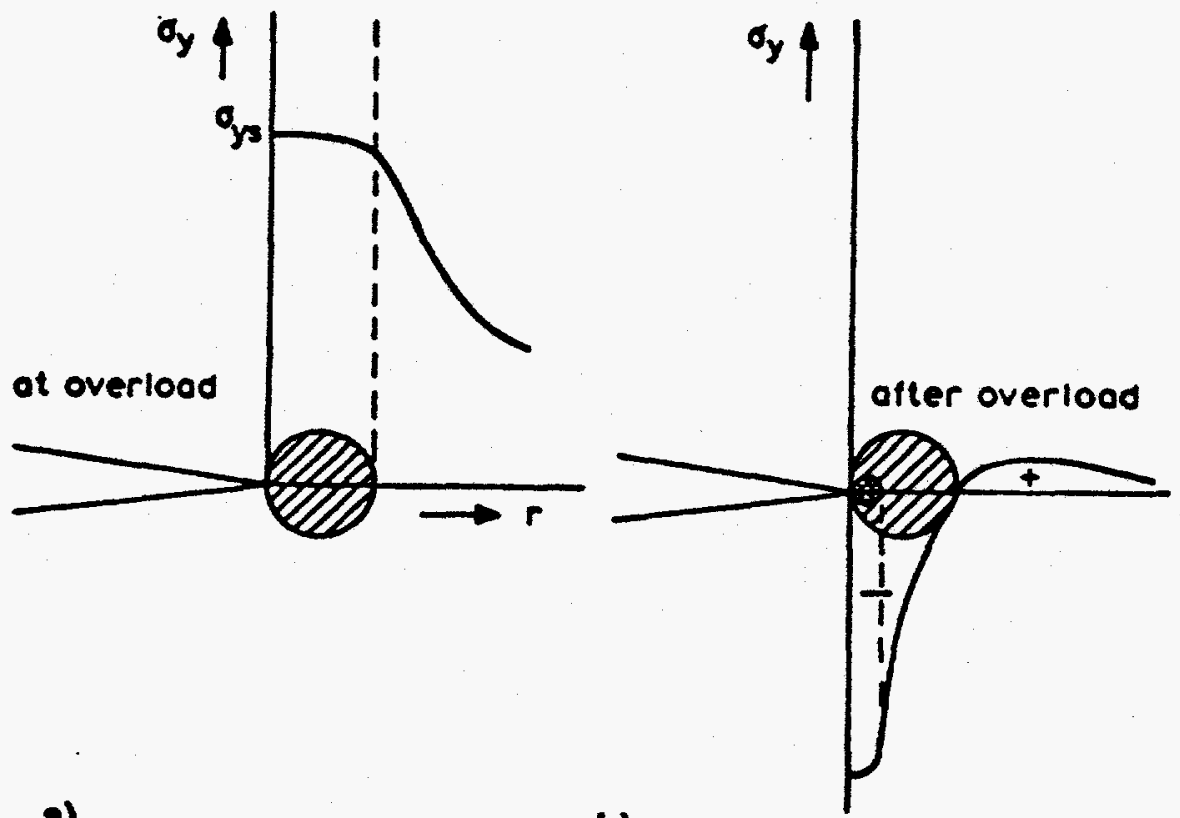

a)

b)

Figure 2. Schematic of the residual compressive stresses at a crack tip as a result of a tensile overload. 


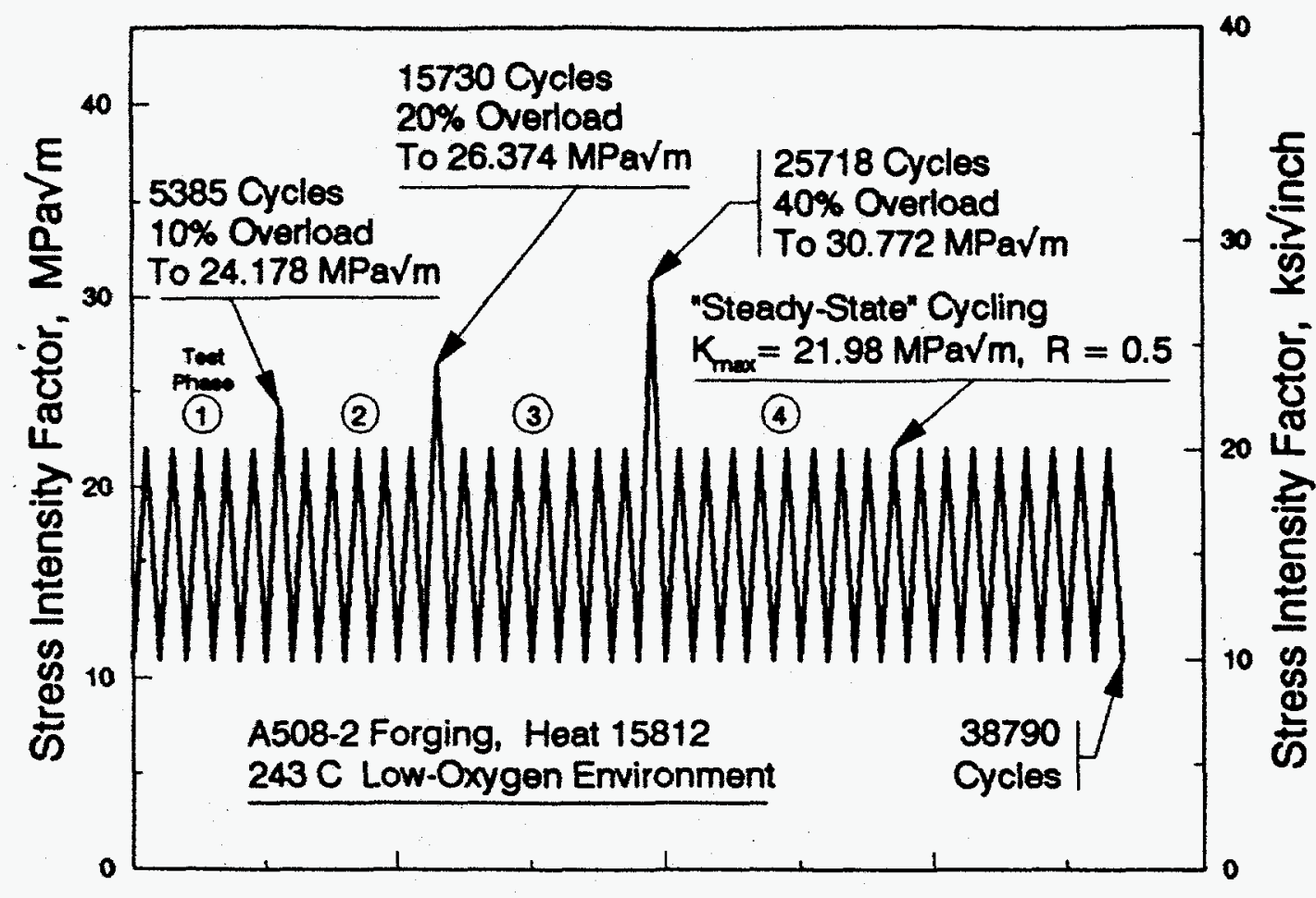

PVPo7a.dAW

\section{Fatigue Cycles}

Figure 3. Schematic illustrating the application of tensile overloads.

"Steady-state" cycling conditions resumed following each overload

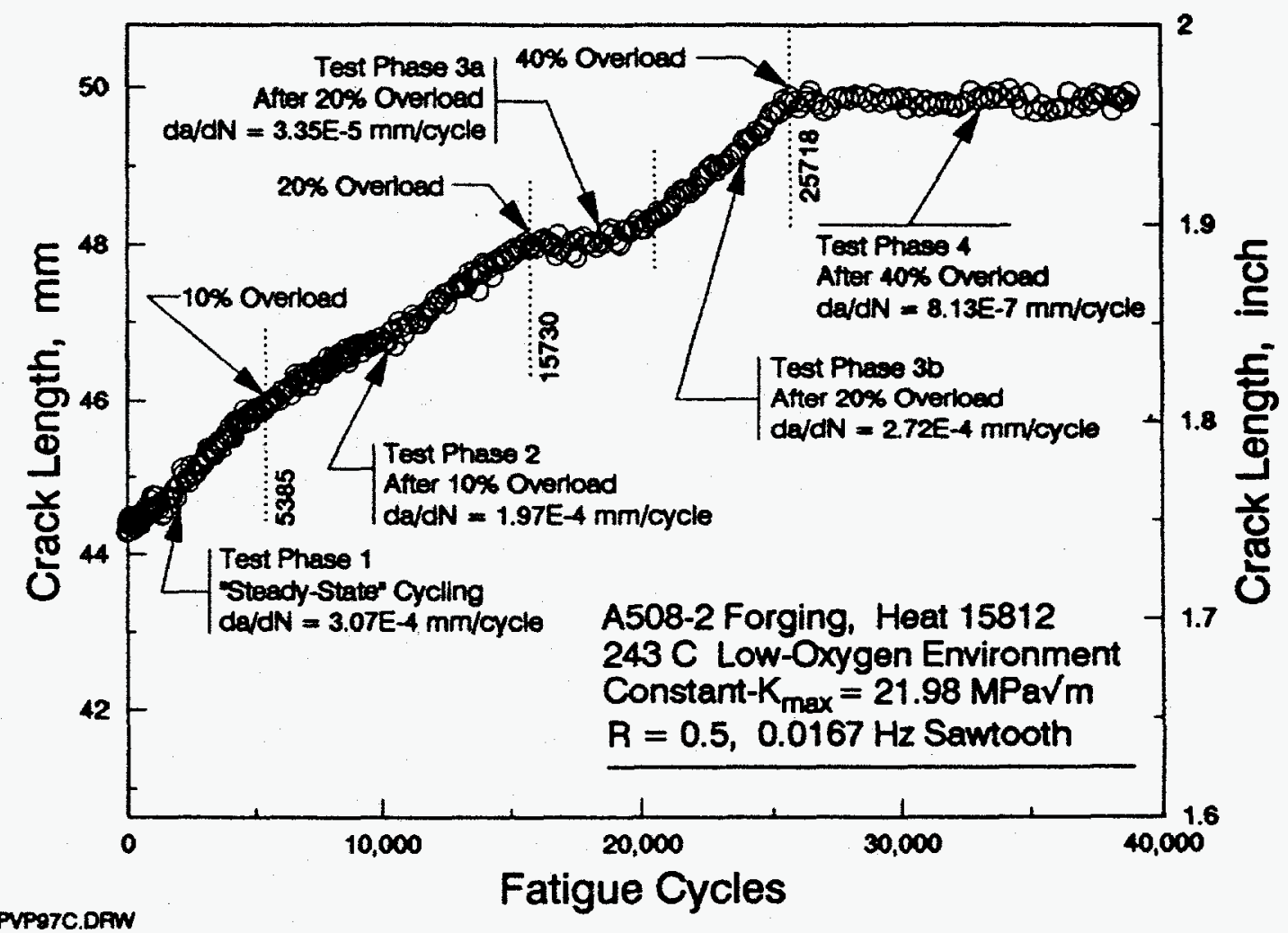

Figure 4. Crack length versus cycles plot showing the effect of tensile overloads 


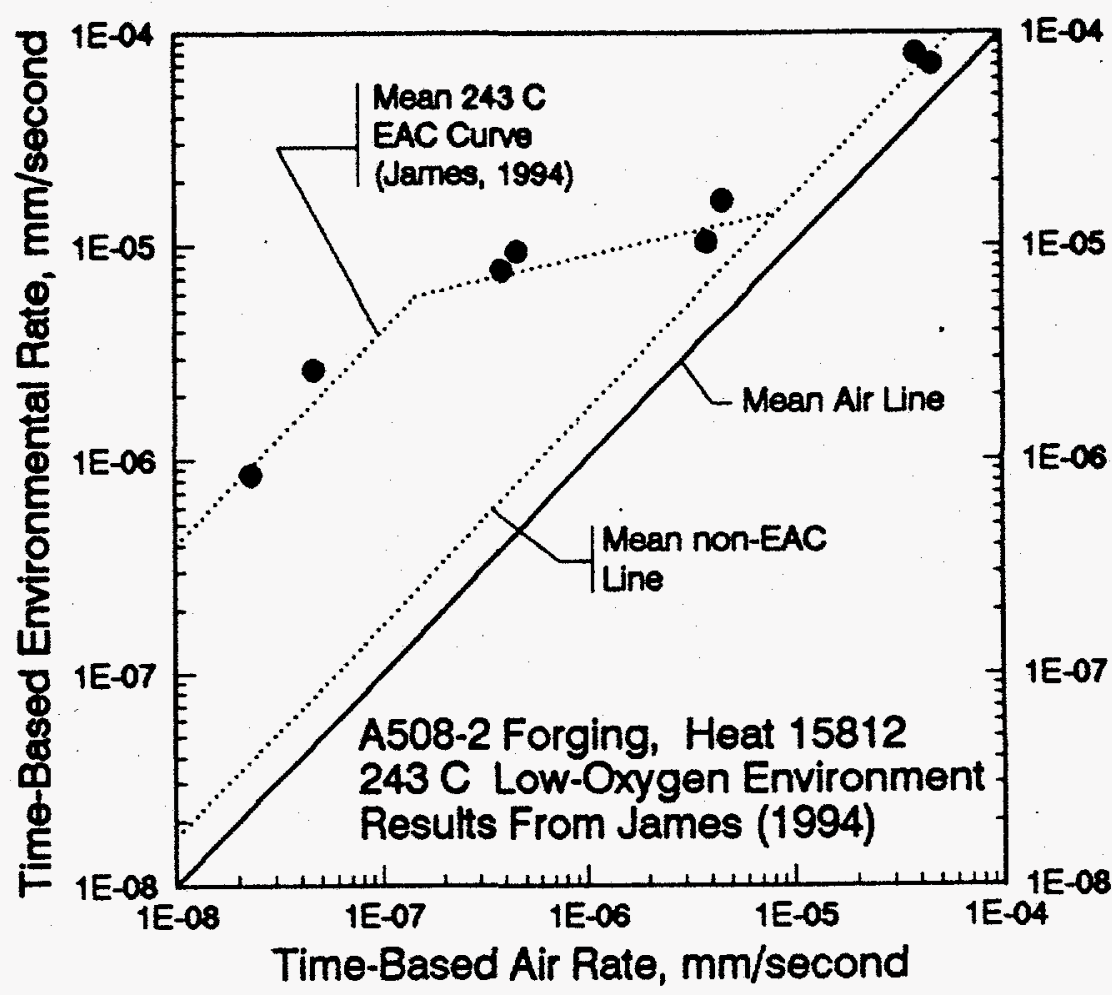

Figure 5. Time-domain plot showing the EAC behavior of Heat 15812 in a $243^{\circ} \mathrm{F}$ low-oxygen environment (from James, 1994)

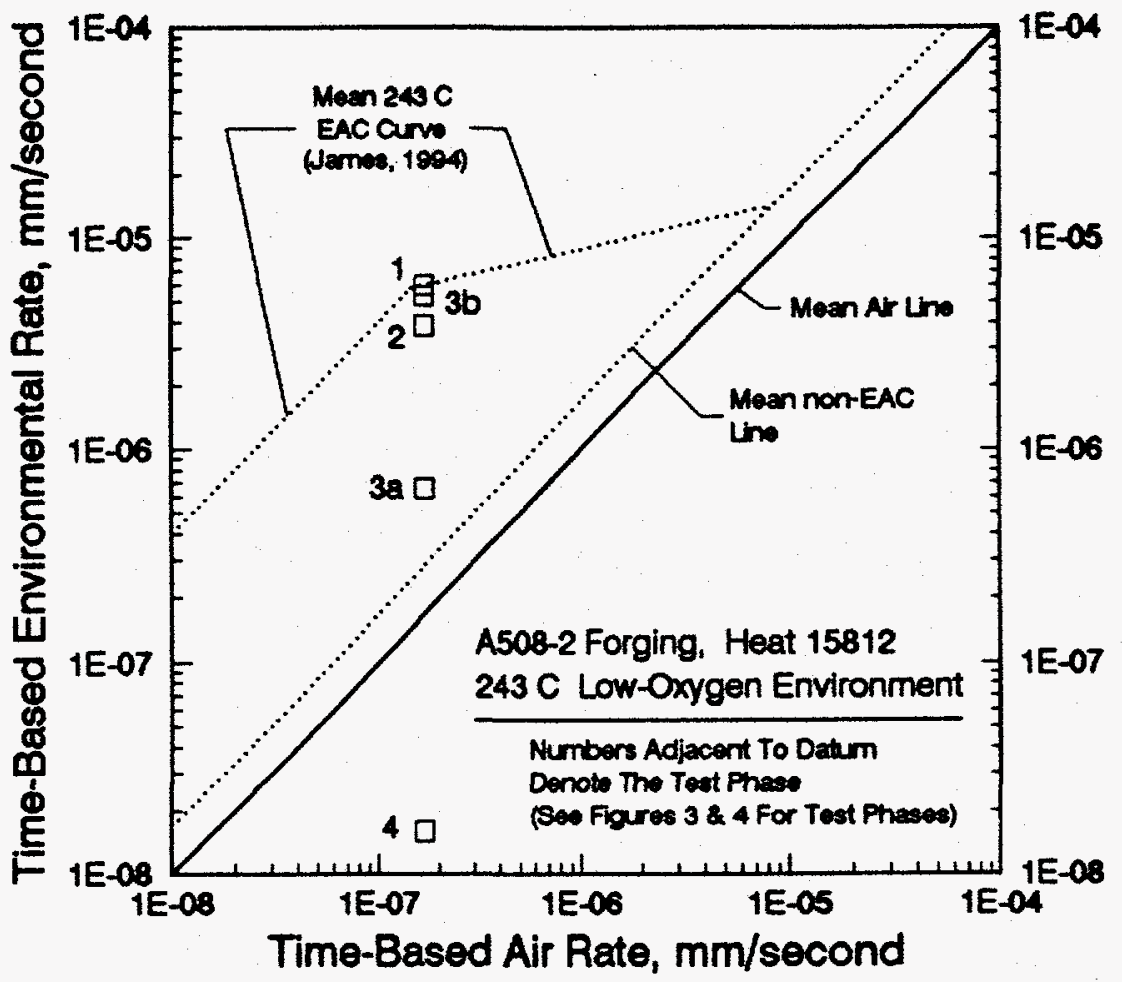

Figure 6. Time-domain plot of the crack growth response to various applied tensile overloads.

See Figure 4 for a definition of the test phases 